\title{
Effect of Macro Environment on the Development of College English Teachers' Information-based Teaching Ability
}

https://doi.org/10.3991/ijet.v13i12.8278

Shen Guo-rong

Henan University of Technology, Zhengzhou, Henan, China

xzc96113@126.com

\begin{abstract}
The macro environment of teachers' professional development involves many factors, including the policies, rules and regulations and the actual development needs of teachers. In terms of the ecological system of Information Technology, from the macro, the factors influencing teachers' survival state includes policy system and teacher training. Based on the questionnaire surveys of three universities with different degrees of Information Technology development, the effect of macro environment on the development of college English teachers' information-based teaching ability is studied and recommendations are given.
\end{abstract}

Keywords - College English teachers, macro environment, incentive mechanism

\section{Introduction}

Outline of the National Medium and Long Term Education Reform and Development Plan (2010-2020 years) points out we have to pay high attention to Information Technology, because it has a revolutionary influence on education development [1]. 10-year Development Plan of Educational Information also points out that to solve the problems restricting the development of education in our country and promote the innovation and reform of education; we have to let education informationization drive education modernization [2]. This is a major strategic choice accelerating a large education country striding forward to an education power; it also puts forward a development and construction target that the combined development level of information technology and education increases significantly [3].

College English Teaching Guide emphasizes that to promote the combination of modern Information Technology and foreign language courses to make the content of college English teaching, teaching methods, learning styles change and realize the effective teaching. The ninth section "teacher development" of the guide also emphasizes that the education policy based on teachers; the quality, level and ability of teachers are the key factors influencing teaching quality. College English teachers have to take the initiative to adapt to the new situation of higher education develop- 
ment, meet the new requirements of college English course system and fulfill the needs of college English teaching development under the informatization environment and constantly improve their professional level and teaching ability. In addition to the mastery of professional disciplines theory and knowledge, they should also have the consciousness of course construction, the ability of choosing teaching content, the ability of adjusting teaching methods and means, the consciousness of taking students as the learning body, the consciousness of teaching reform and the application ability of modern education technology[4].

The ecological environment of college English teachers refers to taking college English teachers as the center, the multidimensional space and multiple environmental systems with restriction and control effect to the college English teachers. Based on the questionnaire surveys of three colleges with different informationization degrees, the effect of macro environment on the development of college English teachers' information-based teaching ability is studied and proper suggestions are put forward.

\section{Literature review}

Fessler in Johns Hopkins University concluded the factors influencing teachers' professional development as individual environment and organizational environment [5]. The American scholar Glatthorn observed that the factors influencing teachers' professional development were the related factors of teachers, the factors related to teachers' life and working situation, the factors related to the special interventions to promote teacher development[6].

Many scholars in China also made researches on the factors influencing teachers' professional development. For example, Liu Jie (2004) divided the basic factors influencing teachers' professional development into social factors (including social status, professional appeal and teacher management system), school factors (including the President's lead, the motivation of cooperative teacher culture, the guarantee of democratic management system) and personal factors (including family factors and professional structure factors)[7]. Wang (2004) divided the factors influencing teachers' professional development into three categories. The first is teachers' personal characteristics; secondly, the teachers' professional life has the characteristics of direct social environment, and the last is the characteristics contributing teacher's professional development[8]. Zhao Changmu and Xu Ji-cun $(2004,2005)$ summed up the factors influencing teachers' professional development as environmental factors (including education policy, school management, and teacher culture and school atmosphere) and personal factors (including cognitive ability, ethics, interpersonal communication, career development motivation and self assessment)[9]. Chun-lei Wang and Mei-feng Liu thought the internal conditions (physiological factors, psychological factors, and ability and work characteristics) and the external environment (human, physical, social and cultural factors) are the factors influencing teachers' effective application of technology[10]. Pei-pei Hu thought the influencing factors included teachers, environment, software, and the student (Pei-pei Hu, 2008a)[11]. Wang Weijun thought the 
influencing factors included teachers, school and social factors (Wang Weijun, 2009 b)[12][13].

Jian-lan $\mathrm{Wu}$ (2007) puts forward some strategies to realize the sustainable development of middle school teachers according to the survey on the present situation of English teachers' professional development in Jiangxi Middle School [14]. Lin Hui (2011) discussed the characteristics of teachers in the micro and macro points, the influence of environmental factors on teachers, and the structure and function of teachers' development of ecosystem; he tried to explore the approaches accelerating the ecological development of Middle School English teachers [15].

Modern education information technology can ultimately be fulfilled in the teaching activity, which largely depends on the key species of the ecosystem in college English teaching - college English teachers. As a part of the whole social ecological system, college English teachers are also in a variety of external environment (including natural environment, social environment and normative environment).Therefore, whether college English teachers use modern information education technology or not is related to external social environment and atmosphere, and have a close correlation with the surrounding people (Shown in Figure 1) [16].

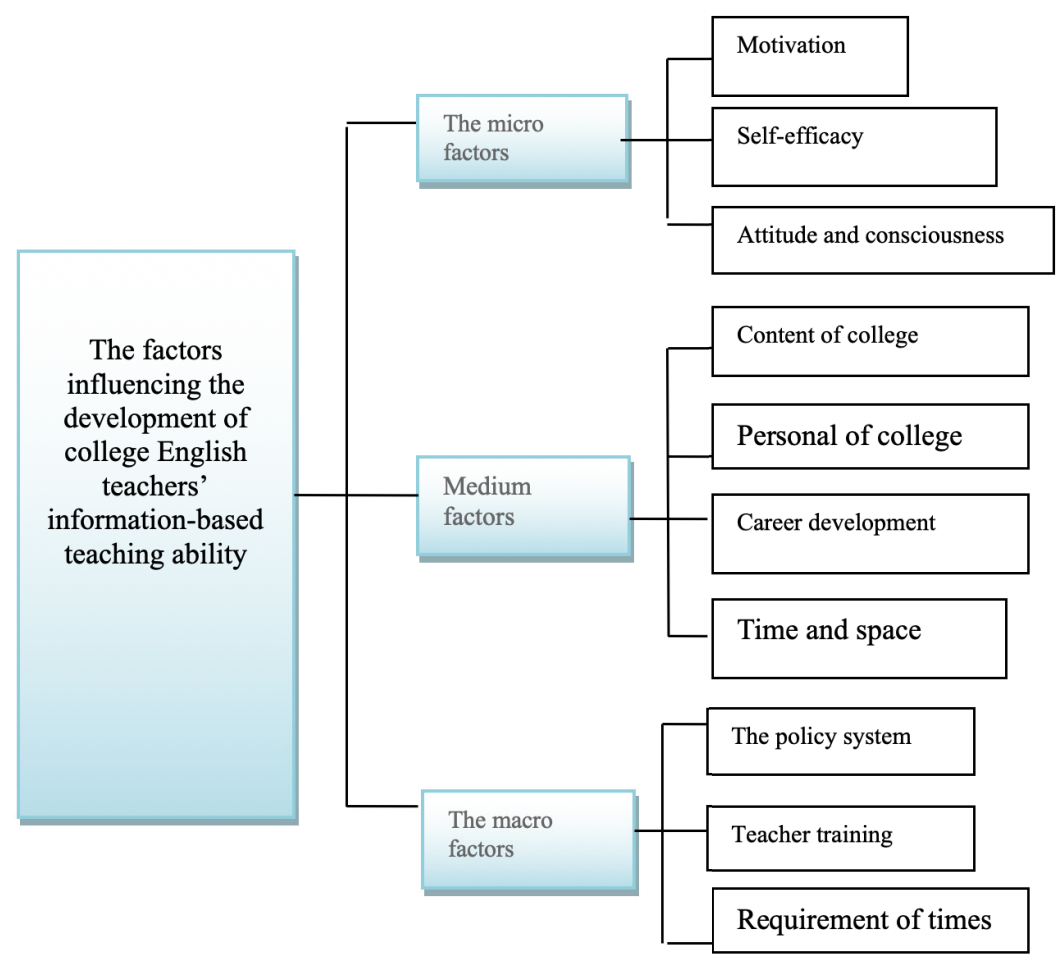

Fig. 1. The factors influencing the development of college English teachers' information-based teaching ability 


\section{$3 \quad$ Research methods}

\subsection{Questionnaire}

For further study of the status of college English teachers' information-based teaching ability, college English teachers' ability using information tools questionnaire" is designed. Questionnaire adopts Likert (Likert scale) level 5 scoring method. 1 is "basically in-conforming"; 2 is "a little conforming"; 3 is "Neither conforming nor inconforming"; 4 is "basically conforming" and 5 is "completely conforming". In May of 2015, the author conducted the questionnaire survey at A, B and C with a sum of 160 college English teachers participating in it. Out of the questionnaires issued, 155 were received. After careful observation and analysis, 5 were eliminate due to choosing the same answer overall or completing only parts of the questionnaire.Thus, 150 effective teachers' questionnaires were taken as the data source of the survey analysis. After careful arrangement, they are stored in SPSS19.0 system for reserve.

\subsection{Interview}

There were five managers (dean of studies, dean of teaching and director) and eight first-line teachers. The interview recording mainly adopted qualitative analysis method for induction and summary. The coding rule is "school code"+ "teachers code"+ "serial number". For example, the interview of Zhengzhou University manager, the code is "AG1"; where, A is the school code; $\mathrm{G}$ is the school manager and 1 represents the director. After the teaching plan is quantified by the cover scale, the data and information is mainly processed by Microsoft Excel 2007. Excel 2007 would be charting data processing.

\section{Data analysis and discussion}

\subsection{The correlation between macro environment and the present situation of college English teachers' information-based teaching ability}

The Marxism thought the world is a widespread contacting whole, which is also suitable for the training of teachers' information-based teaching ability. Times' requirement is the macro factor influencing teacher's information-based teaching ability.

Pearson's correlation coefficient when applied to a sample is commonly represented by the letter $r$ and may be referred to as the sample correlation coefficient or the sample Pearson correlation coefficient. We can obtain a formula for $r$ by substituting estimates of the co-variances and variances based on a sample into the formula above. So if we have one dataset $\{\mathrm{x} 1, \ldots, \mathrm{xn}\}$ containing $\mathrm{n}$ values and another dataset $\{\mathrm{y} 1, \ldots, \mathrm{yn}\}$ containing $\mathrm{n}$ values then that formula for $\mathrm{r}$ is[17]: 


$$
r=\frac{\sum_{i=1}^{n}\left(x_{i}-\bar{x}\right)\left(y_{i}-\bar{y}\right)}{\sqrt{\sum_{i=1}^{n}\left(x_{i}-\bar{x}\right)^{2}} \sqrt{\sum_{i=1}^{n}\left(y_{i}-\bar{y}\right)^{2}}}
$$

Table 1. The correlation between macro environment and the present situation of college English teachers' information-based teaching ability

\begin{tabular}{|l|c|c|c|}
\hline & system & Time request & training \\
\hline $\begin{array}{l}\text { the present situation of college English } \\
\text { teachers' information-based teaching } \\
\text { ability }\end{array}$ & $.569^{* *}$ & $.412^{* *}$ & $.347^{* *}$ \\
\hline
\end{tabular}

** When the confidence coefficient (Double test) is 0.01 , the correlation is significant.

Table 1 shows the correlation coefficient between system, times' requirement, training and the present situation of college teachers' information-based teaching ability respectively.

\subsection{Development of information-based teaching ability and macro ecological impact factor}

Anything cannot break away from the external environment to develop, and the development of teachers' information-based teaching ability is impossible to develop separating from the external environment.

The policy and system mainly includes whether the country or region issues guidance documents and implementation plan related to the development and whether it carries out some policies and systems to promote its development.

Table 2. The influencing of policy and system on the development of college English teachers' information-based teaching ability

\begin{tabular}{|l|c|c|c|c|c|}
\hline & N & Minimum & Maximum & $\begin{array}{l}\text { Mean } \\
\text { value }\end{array}$ & $\begin{array}{l}\text { Standard } \\
\text { deviation }\end{array}$ \\
\hline $\begin{array}{l}\text { 1. I have read the National Medium and Long- } \\
\text { term Educational Reform and Development } \\
\text { Program (2010-2020) and Several Require- } \\
\text { ments on Comprehensively Improving the } \\
\begin{array}{l}\text { Quality of Higher Education by the Ministry of } \\
\text { Education. }\end{array}\end{array}$ & 150 & 1 & 5 & 3.59 & 1.362 \\
\hline $\begin{array}{l}\text { 2. I have read the National Educational Tech- } \\
\text { nology Guide for teachers in Higher Educa- } \\
\text { tion and Regulations on the Qualifications of } \\
\text { Teachers }\end{array}$ & 150 & 1 & 5 & 2.83 & 1.266 \\
\hline $\begin{array}{l}\text { 3. I have read the related content relating to } \\
\text { information-based teaching in Teaching Re- } \\
\text { quirements of College English Curriculum and } \\
\text { Teaching Guide of College English. }\end{array}$ & 150 & 1 & 5 & 3.88 & 1.023 \\
\hline Effective N(List state) & & 150 & & & \\
\hline
\end{tabular}


In the questionnaire of ecological impact factor on college teachers' informationbased teaching ability development, the mean value of item 1 is $\mathrm{M}=3.59$, which shows most of teachers have read the National Medium and Long-term Educational Reform and Development Program (2010-2020). They would not know the education form, the training goal in national education and teaching, and teacher's development goal at the present stage if teachers have never touched or lacked learning on the plan. The mean value of item 2 is $\mathrm{M}=2.83$, which shows most of teachers have not read the National Educational Technology Guide for Teachers in Higher Education and Regulations on the Qualifications of Teachers. National Educational Technology Guide for Teachers in Higher Education describes the education technology ability of college teachers from the angle of 5 dimensions, 17 secondary indexes and 54 triple performance indicators and related structure modes are built on this basis. This largely points out the direction for the promotion of college teachers' education technology ability and provides guarantees for the improvement of teaching quality in some degree. If teachers almost never know Regulations on the Qualifications of Teachers and they would not know the new requirements on teachers' educational teaching ability in the Internet era and cannot keep up with the times. The mean value of item 3 is $\mathrm{M}=3.8$. Even though it does not reach the representation of "conforming", it approaches the score of 4 (conforming) and is higher than the value of item 27 and 28 . That illustrates that compared with the plan, teachers are more familiar with the curriculum requirements and ideas and guidelines in it. Through a semi structured interview, the interviewed teachers reflected that they had different approaches on knowing the course requirements, such as the transmission of department heads and to participate in teaching reform training.

"In terms of learning course requirements and taking part in teaching reform training, I know the direction for the future development of college English teaching and the impact on teachers caused by this, and thus know the orientation of the study", AT5 said.

Teachers' training. The course contents of pre-job or on-the-job training would also have a certain influence on teachers' information-based teaching ability.

Table 3. The influence of teachers' training on the development of college English teachers' information-based teaching ability

\begin{tabular}{|l|c|c|c|c|c|}
\hline & N & Minimum & Maximum & $\begin{array}{c}\text { Mean } \\
\text { value }\end{array}$ & $\begin{array}{c}\text { Standard } \\
\text { deviation }\end{array}$ \\
\hline $\begin{array}{l}\text { 4. Information technology training in national } \\
\text { level has large effect on improving my infor- } \\
\text { mation-based teaching. }\end{array}$ & 150 & 1 & 5 & 4.02 & 1.102 \\
\hline $\begin{array}{l}\text { 5. The country should build a macro infor- } \\
\text { mation-based platform for teachers' training. }\end{array}$ & 150 & 1 & 5 & 3.85 & 1.217 \\
\hline $\begin{array}{l}\text { 6. The country should improve college Eng- } \\
\text { lish teachers' pre-job and on-the-job training } \\
\text { system. }\end{array}$ & 150 & 1.0 & 5.0 & 3.917 & 1.0609 \\
\hline Effective N (List state) & 150 & & & & \\
\hline
\end{tabular}


In the questionnaire of ecological impact factor on the development of college teachers' information-based teaching ability, the mean value of item 4 is $M=4.0$; that shows college English teachers have to strengthen training and improve their information literacy and information skills based on modern information technology. Therefore, college English teachers need to actively participate in various training activities to strengthen the learning of modern information technology particularly, continuously accept new ideas and new things and constantly expand their learning field in the training, improve the basic ability of use of modern information technology flexibly. The mean value of item 5 is $M=3.85$ and item 6 is $M=3.917$, which shows that most of teachers think that the country can improve the level of teachers' information-based teaching by means of pro-job and on-the-job training system and information platform for teachers' training. BT3 have participated in many courses training and teaching reform. Through these trainings, her understanding on the concept of foreign language teaching is gradually deepened, and her description as follows:

"Each summer vacation, I participate in college English teaching reform at the invitation of press, and there is new harvest every year. Famous experts and scholars in the country suggest prospective for the reform of college English in the meeting. I can know the advanced teaching idea, reflect my teaching methods, and make my own effort to improve the level of business at the same time. Our office also organizes the learning and listens to everyone's advice, which plays a very big role to develop our work."

Times' requirements. High-tech, big data, information, economic globalization and the internationalization of education is the pronoun of the 21 st century[18]. Information and the development of network technology overturn the traditional thinking mode. Under such a background, the target, mode, methods, meanings and process of teaching have great changes. Implementation of innovative education, training of innovative talents and education informationization acceleration are the strategic high ground for the long-term development of education in China. This puts forward a higher requirement to teachers and students, especially for college English teachers; whether they respond to the call of times, conforming to the development of times and how to respond and conform to it, which is an issueussed.

Table 3. The influence of times' requirements on the development of college English teachers' information-based teaching ability

\begin{tabular}{|l|c|c|c|c|c|}
\hline & N & Minimum & Maximum & $\begin{array}{c}\text { Mean } \\
\text { value }\end{array}$ & $\begin{array}{c}\text { Standard } \\
\text { deviation }\end{array}$ \\
\hline $\begin{array}{l}\text { 7. I know large-scale online open courses } \\
\text { MOOCs and the challenges for college Eng- } \\
\text { lish education. }\end{array}$ & 150 & 1 & 5 & 3.89 & 1.106 \\
\hline $\begin{array}{l}\text { 8. I know the basic ideas of Flipped Class- } \\
\text { room and try to practice this kind of teaching } \\
\text { mode. }\end{array}$ & 150 & 1 & 5 & 3.85 & 1.114 \\
\hline $\begin{array}{l}\text { 9. A new type of network- micro class, pro- } \\
\text { vide broad playing space for college English } \\
\text { teachers' teaching. }\end{array}$ & 150 & 1 & 5 & 3.72 & 1.205 \\
\hline Effective N (List state) & 150 & & & & \\
\hline
\end{tabular}


In the questionnaire of ecological impact factor on the development of college teachers' information-based teaching ability, the mean value of item 7 is $M=3.89$; item 8 is $M=3.85$ and item 9 is $M=3.72$; which shows that most of college English teachers have realized that they are unable to stay out in the era of change even it is the language discipline. Information technology has deeply affected the language learning. In the $1990 \mathrm{~s}$, computers became popular. Today of the 21 st century, whether we can skillfully use computer has become one of very important skills of people's living and working. Therefore, combining Information Technology ability and foreign language teaching mode has become a magic weapon for a foreign language teacher to win competition. The idea of MOOC is emphasizing innovation and fully opening. So to speak, the idea of MOOC is the reflection of its soul and daring to face big challenges. (Xinmin Sang, et al. 2013: 30-41)。

Among the interviewed 23 teachers, except for two teachers do not know MOOCs and Flipped Classroom, all other teachers know it without deep understanding. They know that "2013 is the year of MOOCs because of the participation of four famous universities (Tsinghua University, Beijing University, Fudan Unversity and Shanghai Jiaotong University) in MOOCs in China, became the first Asian college members of edX, MOOCs times began".(CT3)

\section{$5 \quad$ Suggestions and Conclusions}

As a part of the whole social ecological system, college English teachers are also in a variety of external environment (including natural environment, social environment and normative environment); policy makers and managers should fully realize the importance of teachers' living condition, reasonable allocation of resources in order as to arouse the enthusiasm of teachers to create the most suitable external development environment [19].

1. The change and adjustment of national language education policy at each time need teachers to adjust themselves and adapt to the request of reform policies, which breaks teachers' original teaching behaviors and approaches in a certain degree, and also poses challenges to the survival and development of teachers. The country implements positive language education policy to makes it support each other, interact each other and combine each other with other ecological factors in order to enlarge the positive efficiency of teachers' development and conductive to the development of teachers.

2. The development of times is bound to produce newborn things; we have to keep pace with the times for era development. The successful invasion of the product of era (innovative talents, MOOCs and Flipped classroom) reflects that teachers combine innovation concept and mode into their own cognitive system[20]. Teachers should be familiar with the nature and characteristics of newborn things and have a certain ability to manage and control. After both reached the common point, it enters the benign evolution stage and the whole ecological system achieves a new equilibrium. 
3. In view of the current difficulties and challenges faced by the various departments, they should cooperate with each other and make full use of Information Technology to build a platform of intelligent network teachers' training. This makes teachers carry out related Information Technology training through the platform, and let them master the latest information of education reform. The establishment of the platform provides a more convenient place for experts and scholars to exchange experience and discuss with each other. Network for teacher training can be a platform from country to province and then to colleges by means of different types of software and data for teacher training.

\section{Acknowledgement}

The work is supported by the National Science Foundation of Science and Technology Department of Henan (No.172400410404) and the National Science Foundation of Department of Education of Henan (No.16A880001) and Higher Education Teaching Reform Project of Henan University of Technology (No. 2017SJGLX299).

\section{References}

[1] http://news.xinhuanet.com/edu/2010-07/29/c_12389320_2.htm [2015-3-15].

[2] http://www.moe.edu.cn/publicfiles/business/htmlfiles/moe/s3342/201203/133322.html [2015-3-15].

[3] http://wyx.zzia.edu.cn/picture/article/11/a1/46/4be219604bd4b253303fc53b48c1/6055feeb -9aa3-419f-9a35-1487c02ef8bb.pdf [2015-3-1].

[4] Teaching Guide of College English (exposure draft). ELT Advisory Board under the Ministry Education, 2015.

[5] Fessler, R. (1985) A model for teacher professional growth and development', in Burke, P. \& Heideman, R. (Eds) Career-Long Teacher Education. Springfield, IL: Charles C Thomas.

[6] Glatthorn, A, (1995) Teacher development, International encyclopedia of teaching and teacher education, Elsevier Science Ltd., 135-138.

[7] Liu Jie, (2004) Analysis on the basic factors influencing teachers' professional development. Journal of Northeast Normal University(Philosophy and social sciences), (6) : 1522.

[8] Jianjun Wang, (2004). Curriculum reform and teachers' professional development, Chengdu: Sichuan Press Group Co.Ltd, Sichuan Education Press.

[9] Changmu Zhao, Jichun Xu, (2004). Analysis on the individual factors of Teachers' growth. Linyi Shizhuan Xuebao, (4): 62-67.

[10] Chunlei Wang, Meifeng Liu, (2004). Factors Analysis of influencing information technology in American on the effective application of school education. Education Research, (2):45-48

[11] Peipei Hu, (2008) Research on the development of the primary and secondary school teachers' education technology ability. Nanjing: Master thesis, Nanjing Normal University.

[12] Weijun Wang, (2009). Research on the development of teachers' information-based teaching ability, Lanzhou: Northwest Normal University. 
Paper-Effect of Macro Environment on the Development of College English Teachers' Information...

[13] Wenjun Wang, Weijun Wang, (2012). Practice Analysis on Teachers' information-based teaching ability. Xian Dai Yuan Ju Li Jiao Yu, (3):67-74.

[14] Jianlan $\mathrm{Wu}$, (2007). Research on the Continuous Development of Middle School Teachers in the view of Ecology. Jiangxi Normal University.

[15] Hui Lin,(2011). Middle School English Teacher Development in the Context of Educational Ecology. Xi'an International Studies University.

[16] Guorong Shen and Jie Li, (2017). Research on the Current Situation and Development Strategy of College English Teachers' Ability to Teaching English with Information Technology. Beijing: China Science Publishing and Media Ltd.

[17] https://en.wikipedia.org/wiki/Pearson_correlation_coefficient

[18] Merja Kauppinen, Carita Kiili, Julie Coiro. (2018) Experiences in Digital Video Composition as Sources of Self-Efficacy Toward Technology Use. International Jour-nal of Smart Education and Urban Society 9:1, pages 1-12. https://doi.org/10.4018/IJSEUS.2018010101

[19] Boulton, H., \& Hramiak, A. (2014). Cascading the use of Web 2.0 technology in secondary schools in the United Kingdom: Identifying the barriers beyond pre-service training. Technology, Pedagogy and Education, 23, 151-165. https://doi.org/10.1080/147593 9X.2013.802994

[20] Voogt, J., \& Knezek, G. (2016). Guest editorial: Technology enhanced quality educa-tion for all - outcomes from EDUsummIT 2015. Educational Technology \& Society, 19 (3), 14.

\section{Author}

Shen Guo-rong is with the School of Foreign Languages, Henan University of Technology, Zhengzhou, Henan, 450053, China.

Article submitted 21 January 2018. Resubmitted 27 July and 06 August 2018. Final acceptance 07 August 2018. Final version published as submitted by the author. 